\title{
Selective Separation of no Carrier added Sc-47 from Reactor Irradiated Ca Using Zirconium Vanadate Gel for Nuclear Medical Applications
}

\author{
M. A. Gizawy a, b, M. I. Aydia a, c *, H. A. Shamsel-Din a, b, K.M. El-Azony ${ }^{\text {c }}$ \\ (a) Radioisotopes Production Facility (RPF), Second Research Reactor (ETRR-2), Egyptian Atomic Energy Authority, Cairo, Egypt. \\ (b) Labelled Compounds Department, Hot Labs Center, Egyptian Atomic Energy Authority, Cairo, Egypt. \\ ${ }^{(c)}$ Radioactive Isotopes and Generator Department, Hot Labs Center, Egyptian Atomic Energy Authority, Cairo, Egypt.
}

\begin{tabular}{|c|c|}
\hline ARTICLE INFO & ABSTRACT \\
\hline $\begin{array}{l}\text { Article history: } \\
\text { Received: } 15^{\text {th }} \text { Apr. } 2021 \\
\text { Accepted: } 1^{\text {st }} \text { July } 2021\end{array}$ & $\begin{array}{l}\text { Various concentrations of } \mathrm{HCl} \text { or } \mathrm{HNO}_{3} \text { on } \mathrm{Zirconium} \text { Vanadate }(\mathrm{ZrV}) \text { gel as an ion } \\
\text { exchanger were studied by batch technique to determine the } \mathrm{K}_{\mathrm{d}} \text { values of }{ }^{47} \mathrm{Ca}(\mathrm{II}) \text { and } \\
{ }^{47} \mathrm{Sc}(\mathrm{III}) \text { ions. A small chromatographic column packed with } \mathrm{ZrV} \text { gel for }{ }^{47} \mathrm{Sc}(\mathrm{III})\end{array}$ \\
\hline $\begin{array}{l}\text { Keywords: } \\
\text { Scandium-47; Calcium-47; } \\
\text { Theranostics, } \\
\text { Reactor produced } \\
\text { radioisotopes, } \\
\text { Ion exchange } \\
\text { chromatography, } \\
\text { Zrconium Vanadates. }\end{array}$ & $\begin{array}{l}\text { separation based on a high elution yield with high purity from the point of view chemical, } \\
\text { radiochemical and radionuclidic. The maximum elution yield of }{ }^{47} \mathrm{Sc}(88 \pm 2.2 \%) \text { was } \\
\text { obtained using } 60 \% \text { acetone- } 0.2 \mathrm{M} \mathrm{HCl} \text { as an eluent. The }{ }^{47} \mathrm{Sc} \text { was separated with } \\
\text { acceptable radionuclidic purity }(>99.98 \pm 0.001 \%) \text { and radiochemical purity }(99.9 \pm 0.09 \%) \text {, } \\
\text { in addition to a very low concentrations of } \mathrm{Ca}^{+2}(0.05 \mathrm{ppm}) \text { which is lower than the } \\
\text { permissible level }(10 \mathrm{ppm}) \text { for medical applications, particularly for the labelling of } \\
\text { pharmaceutical compounds. }\end{array}$ \\
\hline
\end{tabular}

\section{INTRODUCTION}

Scandium-47 is a promising candidate that can be used for therapeutic applications in low-energy betaparticle therapy $\left(\mathrm{E}_{\beta}-=440.7 \mathrm{keV}, \mathrm{I}_{\beta}=68.4 \% ; 600.1 \mathrm{keV}\right.$, $\mathrm{I}_{\beta}=31.6 \%$ ) that is primarily aimed for the small tumors $[1,2]$. In addition, the ${ }^{47} \mathrm{Sc}$ half-life is short $\left(\mathrm{T}_{1 / 2}=3.35\right.$ d) and would be motivated to label small organic molecules. Separation of ${ }^{47} \mathrm{Sc}$ radionuclide with a high purity is a primary issue for labelling a variety of pharmaceuticals that have biological applications [3, 4]. Two different neutron-induced reactions based on neutron energy were used to produce ${ }^{47} \mathrm{Sc}$ [5-8]. Fast neutrons with energy greater than $1 \mathrm{MeV}$ were used via ${ }^{47} \mathrm{Ti}(\mathrm{n}, \mathrm{p})$ reaction for the ${ }^{47} \mathrm{Sc}$ production [9], while thermal neutrons $\left(E_{n}=0,025 \mathrm{eV}\right)$ used via the ${ }^{46} \mathrm{Ca}(\mathrm{n}, \gamma)^{47} \mathrm{Ca} \stackrel{\beta^{-}}{\rightarrow}{ }^{47} \mathrm{Sc}$ reaction [2]. Calcium contains six stable isotopes of natural abundance, such different radionuclides can be produced by irradiation using thermal neutrons as seen in Scheme (1). Scandium and calcium radioisotopes have not been detected by gammaanalysis of the irradiated calcium target, with the exception of ${ }^{47} \mathrm{Sc}$ and ${ }^{47} \mathrm{Ca}$ radionuclides [8]. The induced proton reaction to the enriched ${ }^{48} \mathrm{Ti}$ target could also be used to produce ${ }^{47} \mathrm{Sc}$ via $(\mathrm{p}, 2 \mathrm{p})$ reaction, but unfortunately ${ }^{46} \mathrm{Sc}\left(\mathrm{t}_{1 / 2}=83.79 \mathrm{~d}\right)$ was co-produced with a high level associated with ${ }^{47} \mathrm{Sc}[10]$. Despite the physical and nuclear properties of ${ }^{47} \mathrm{Sc}$, which refers to its potential to be used as a theragnostic agent, there are different factors that hindered the production of ${ }^{47} \mathrm{Sc}$, such as the high cost of the enriched target [7]. Several separation methods have been performed on the irradiated natural calcium target to achieve a high separation yield for ${ }^{47} \mathrm{Sc}$ with high radiochemical, radionuclidic and chemical purity based on solvent extraction such as tributyl phosphate [11] and ion exchange technique using different exchangers [12-22]. Synthetic inorganic ion exchangers are still more widely used due to their substantial advantages over organic resins $[23,24]$. They are characterized by their higher thermal stability at elevated temperatures and resistance to high radiation doses, as well as their selectivity to some ions, which are properties that appear to lack organic resins. In comparison with organic ionexchangers, synthetic inorganic ion exchangers have a high sensitivity to radionuclides and work over a broad $\mathrm{pH}$ range [25-29]. 
The current study concerns the use of zirconium vanadate $(\mathrm{ZrV})$ as an inorganic sorbent for the effective ${ }^{47} \mathrm{Sc}$ separation technique from the neutron irradiated natural calcium target with excellent yield and chemical form valid for radiolabelling. Then, comparing the results obtained with the literature results in order to show the validity of this procedure.

\section{Experimental}

\section{Chemicals}

Zirconium oxychloride $\left(\mathrm{ZrOCl}_{2} \cdot 2 \mathrm{H}_{2} \mathrm{O}\right)$ from SigmaAldrich and sodium vanadate $(99.98 \%)$ from Merk, both of AR grade, were bought without further purification. Other chemical reagents used in this study were of analytical purity and were used without further purification. Double distilled water was used to prepare all solutions.

\section{Instrument}

Several techniques were used to investigate the chemical structure of the $\mathrm{ZrV}$ gel. The FTIR spectrum of $\mathrm{ZrV}$ gel was studied in the $400-4000 \mathrm{~cm}^{-1}$ range to identify the functional groups in the $\mathrm{ZrV}$ gel. The X-ray diffractometer (XRD) (X-lab Shimadzu X-6000) used a wavelength of $1,54^{\circ} \mathrm{A}, \mathrm{Cu}-\mathrm{K} \alpha$ for quantitative and qualitative analysis.. High-purity germanium detector (HPGe), $\gamma$-ray spectrometer (GX2518 model, Canberra, USA) connected to a multi-channel analyzer used to detect radionuclides impurities in the final product. Inductive coupled plasma-atomic emission spectroscopy (ICP-AES) is used to determine calcium impurity in the eluted ${ }^{47} \mathrm{Sc}$ after ensuring its decay.

\section{Preparation of $\mathrm{ZrV}$ matrix}

Both zirconium oxychloride and sodium vanadate were used in the AR grade. Amorphous ranges of zirconium vanadate were prepared according to Roy's method [27] by the following steps: A drop by drop of $100 \mathrm{ml}$ sodium vanadate solution $(0.1 \mathrm{M})$ was added to $50 \mathrm{ml}$ of zirconium oxychloride solution $(0.1 \mathrm{M})$ by continuous stirring and dissolved in $2 \mathrm{M} \mathrm{HCl}$. The mixture solution was water-diluted to 1 litre, and then allowed to settle for 24 hours. Several times the precipitate was washed with deionized water, then filtered and washed again with hot water to remove the excess chloride. The $\mathrm{pH}$ of the final solution moved slightly to the acidic medium at about $\mathrm{pH} 4$.

\section{${ }^{47} \mathrm{Sc}$ and ${ }^{47} \mathrm{Ca}$ radiotracers}

Approximately $1 \mathrm{~g}$ of natural $\mathrm{CaCO}_{3}$ was weighed accurately and encased in thin aluminum foil that was wiped with acetone-moistened cotton and air-dried prior to use. The sample of $\mathrm{CaCO}_{3}$ target was inserted in an aluminium container, enclosed and tested for leakage, and then irradiated for 24 hours in the $22 \mathrm{MW}$ water-cooled Egyptian Research Reactor (ETRR-2) with a thermal neutron flux of approximately $1.8 \times 10^{14} \mathrm{n} / \mathrm{cm}^{2}$.S. The radioactive target was decided to leave for 3 days to decay short-lived radionuclides and then dissolved in $5 \mathrm{ml}$ of $0.1 \mathrm{M} \mathrm{HCl}$ acid. The solution was changed to steam by heating and was almost dry, and finally dissolved in $10 \mathrm{ml}$ of deionized water. All scandium and calcium radioisotopes that could be produced and were discussed in Scheme.1.

\section{Chemical species produced in the aqueous solutions based on chemical equilibrium diagrams}

Chemical structure evaluation based on preparation solution evolution was modeled using chemical equilibrium diagrams [30] to give perspective into the available cation and anion species at the beginning of the reaction in order to interpret the sorption behavior of calcium and scandium species at a specific $\mathrm{pH}$ onto $\mathrm{ZrV}$ matrix.

\section{Acid-base titration of $\mathrm{ZrV}$ gel}

$100 \mathrm{mg} \mathrm{ZrV}$ gel specimens were placed in $25 \mathrm{ml}$ glass bottles, divided into two sets and equilibrated with different volumes of $0.1 \mathrm{M} \mathrm{NaCl} \& 0.1 \mathrm{M} \mathrm{M} \mathrm{HCl}$ in the first set and $0.1 \mathrm{M} \mathrm{NaCl} \& 0.1 \mathrm{M} \mathrm{NaOH}$ in the second set with preserving an ionic strength equal to $0.1 \mathrm{M}$ and a total volume of $10 \mathrm{ml}$ in each bottle and left overnight at $25^{\circ} \mathrm{C}$. The $\mathrm{pH}$ value was measured in each bottle and plotted against the concentration of $\mathrm{H}^{+}$(meq) per gram of $\mathrm{ZrV}$ gel in the first set and the concentration of $\mathrm{OH}^{-}$(meq) per gram of $\mathrm{ZrV}$ gel in the second set showing the acid-base titration curve for $\mathrm{ZrV}$ gel.

\section{Batch experiment}

The effect of the initial concentrations of $\mathrm{HCl}$ or $\mathrm{HNO}_{3}$ on the absorption behavior of ${ }^{47} \mathrm{Sc}$ (III) and ${ }^{47} \mathrm{Ca}$ (II) ions on $\mathrm{ZrV}$ matrix was studied by equilibrating $100 \mathrm{mg}$ of the exchanger with $10 \mathrm{ml}$ of various concentration of $\mathrm{HCl}$ or $\mathrm{HNO}_{3}$ with $300 \mu$ of radioactive tracers of ${ }^{47} \mathrm{Sc}$ and ${ }^{47} \mathrm{Ca}$ in $25 \mathrm{ml}$ glass bottles shaken at $25^{\circ} \mathrm{C}$ in a thermostat shaker $(140 \mathrm{rpm})$. Solutions were jolted for 24 hours, then the shaker stopped and the solid phases settled down. One $\mathrm{ml}$ of the aqueous phase was withdrawn and radioactivity was measured for ${ }^{47} \mathrm{Sc}$ and ${ }^{47} \mathrm{Ca}$. The $\mathrm{K}_{\mathrm{d}}$ value of ${ }^{47} \mathrm{Sc}$ (III) and ${ }^{47} \mathrm{Ca}$ (II) from $\mathrm{HCl}$ or $\mathrm{HNO}_{3}$ solution to $\mathrm{ZrV}$ matrix was calculated using the following equation: 


$$
\boldsymbol{K}_{\boldsymbol{d}}=\left(\boldsymbol{A}_{\mathrm{o}}-\boldsymbol{A}_{\boldsymbol{e}}\right) \times \boldsymbol{V} / \boldsymbol{A}_{\boldsymbol{e}} \times \boldsymbol{m} \quad(\mathrm{ml} / \mathrm{g})
$$

Where $\left(\mathrm{A}_{\mathrm{o}}\right)$ and $\left(\mathrm{A}_{\mathrm{e}}\right)$ are the aqueous phase counting rates before and after equilibration, respectively, $(\mathrm{V})$ is the aqueous phase volume $(10 \mathrm{ml})$ and $(\mathrm{m})$ is the matrix weight (100 mg of $\mathrm{ZrV}$ ). All measurements were repeated in triplicate, estimating the average values of $\mathrm{K}_{\mathrm{d}}$.

\section{${ }^{47}$ Sc separation via column technique}

The glass column $(10 \mathrm{~cm}$ long $\times 0.5 \mathrm{~cm}$ inner diameter) was first filled with $0.001 \mathrm{M} \mathrm{HNO}_{3}$, followed by the addition of $600 \mathrm{mg}$ of the prepared $\mathrm{ZrV}$ matrix to obtain a bed volume of about $1 \mathrm{ml}$. After the particles of the exchanger were settled down in the column, the quartz wool was located on the top of the exchanger to prevent any disruption of the packed column surface. The radioactive tracers of ${ }^{47} \mathrm{Sc}$ and ${ }^{47} \mathrm{Ca}$ in $0.001 \mathrm{M} \mathrm{HNO}_{3}$ were passed through the loading column, followed by a $10 \mathrm{ml}$ mixture of $0.2 \mathrm{M} \mathrm{HCl}$ with $60 \%$ acetone solution for ${ }^{47} \mathrm{Sc}$ elution. In symmetrical glass bottles, both ${ }^{47} \mathrm{Sc}$ and ${ }^{47} \mathrm{Ca}$ radionuclides were radiometrically measured the flow rate passing through the column is $0.5 \mathrm{ml} / \mathrm{min}$ and equal amounts of the effluent were gathered.

\section{Quality control on the separated ${ }^{47} \mathrm{Sc}$}

The eluted ${ }^{47} \mathrm{Sc}$ in aqueous solution $(60 \%$ acetone in $0.2 \mathrm{M} \mathrm{HCl}$ )) was heated to almost dry, then dissolved in
$500 \mu \mathrm{l}$ of deionized water to perform quality control tests.

\section{Radiochemical purity}

The radiochemical purity of the ${ }^{47} \mathrm{Sc}$ (III) was evaluated using two strips of Whatman No.1 moving up paper chromatography. A solution mixture 1:1 ratio of dilute acetic acid in water was used as a developer for the first strip and for the second strip a saline solution used $(0.9 \% \mathrm{NaCl}$ solution) [31]. The radioactive solution $(\sim 10 \mu \mathrm{l})$ was spotted at the indicated point using a syringe needle and the strip was then placed in a jar containing about $2 \mathrm{ml}$ of the above-mentioned solvent. After the solvent was developed to a specific front position, the strip was allowed to dry, snip into $0.5 \mathrm{~cm}$ pieces and counted separately using the gammascintillation counter. The $\mathrm{R}_{\mathrm{f}}$ was then calculated for each solvent employed.

\section{Chemical purity}

The eluted solution was left for a suitable time to ensure the decay of ${ }^{47} \mathrm{Sc}$ and other long-lived scandium radionuclides, such as ${ }^{46} \mathrm{Sc}\left(\mathrm{t}_{1 / 2}=83.8 \mathrm{~d}\right)$, then a sample was analyzed using inductively coupled plasma atomic emission spectroscopy (ICP-AES) to determine the calcium ion impurity concentration.
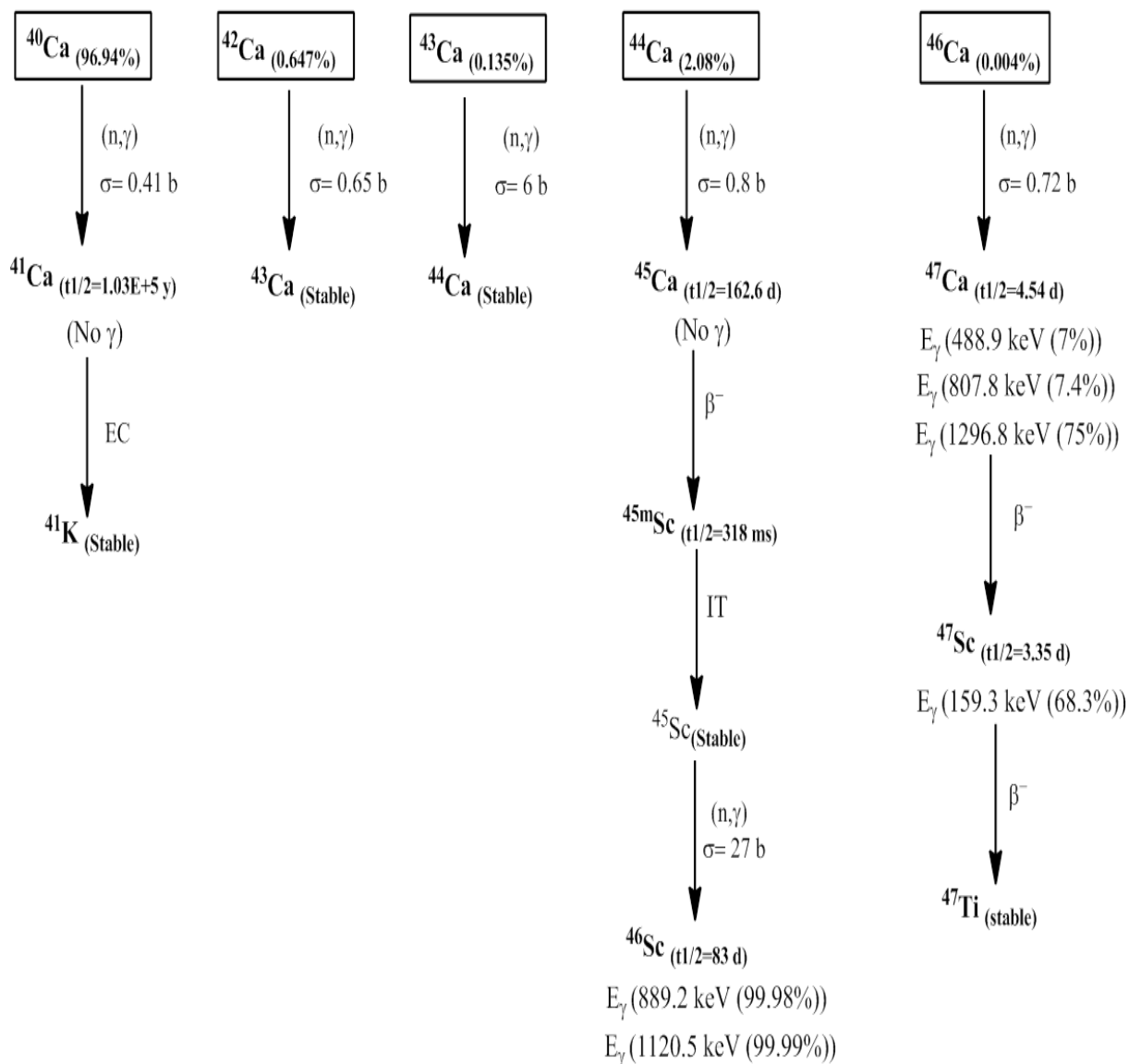

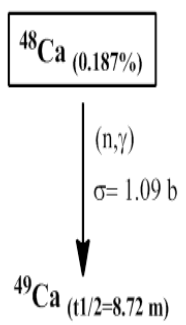

$\mathrm{E}_{\gamma}(3084.4 \mathrm{keV}(90.72 \%))$

$\mathrm{E}_{\gamma}(4071.4 \mathrm{keV}(8.1 \%))$

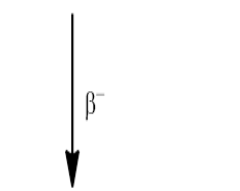

${ }^{49} \mathrm{Sc}_{(\mathrm{t} 1 / 2=57,3 \mathrm{~m})}$

$\mathrm{E}_{\gamma}(1762 \mathrm{keV}(0.05 \%))$

$\mathrm{E}_{\gamma}(1623 \mathrm{keV}(0.01 \%))$

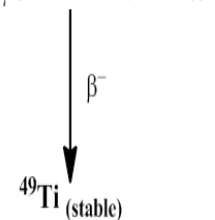

Scheme. (1): Irradiation Scheme of natural calcium target by thermal neutrons for the production of scandium radioisotopes 


\section{Radionuclidic purity}

After the elution process, the separated ${ }^{47} \mathrm{Sc}$ was directly measured using the HPGe detector connected to multichannel analyzer ( $\gamma$-analysis) to detect any radionuclide impurity. Furthermore, the purity of ${ }^{47} \mathrm{Sc}$ was determined as a function of time by measuring its gross radioactive gamma decay.

\section{RESULTS AND DISCUSSION}

\section{FT-IR spectrum}

The FT-IR spectrum of prepared $\mathrm{ZrV}$ gel is shown in Fig. 1. and the vibrations are listed in Table (1). The broad absorption band 3000-3700 $\mathrm{cm}-1$ corresponds to $\mathrm{O}-\mathrm{H}$ in adsorbed water molecules and intermolecular hydrogen bonds. The sharp peak was assigned to the $\mathrm{H}-\mathrm{O}-\mathrm{H}$ bending at $1621.7 \mathrm{~cm}^{-1}$. The vibration of metal-OH could be attributed to the emerging peak at $1402 \mathrm{~cm}^{-1}$ [32]. The perception of the characteristic vanadate peaks, in accordance with Geng et al. 2014[33], is that of the intense, broad band with weak shoulder resolution at the peaks of $984.3,817$ and $703 \mathrm{~cm}^{-1}$ correlate to the symmetrical and asymmetrical stretching/bending $\mathrm{V}-\mathrm{O}$ vibrations. The $\mathrm{Zr}-\mathrm{O}$ stretch vibration is shown in the $435.75 \mathrm{~cm}^{-1}$ band [27].

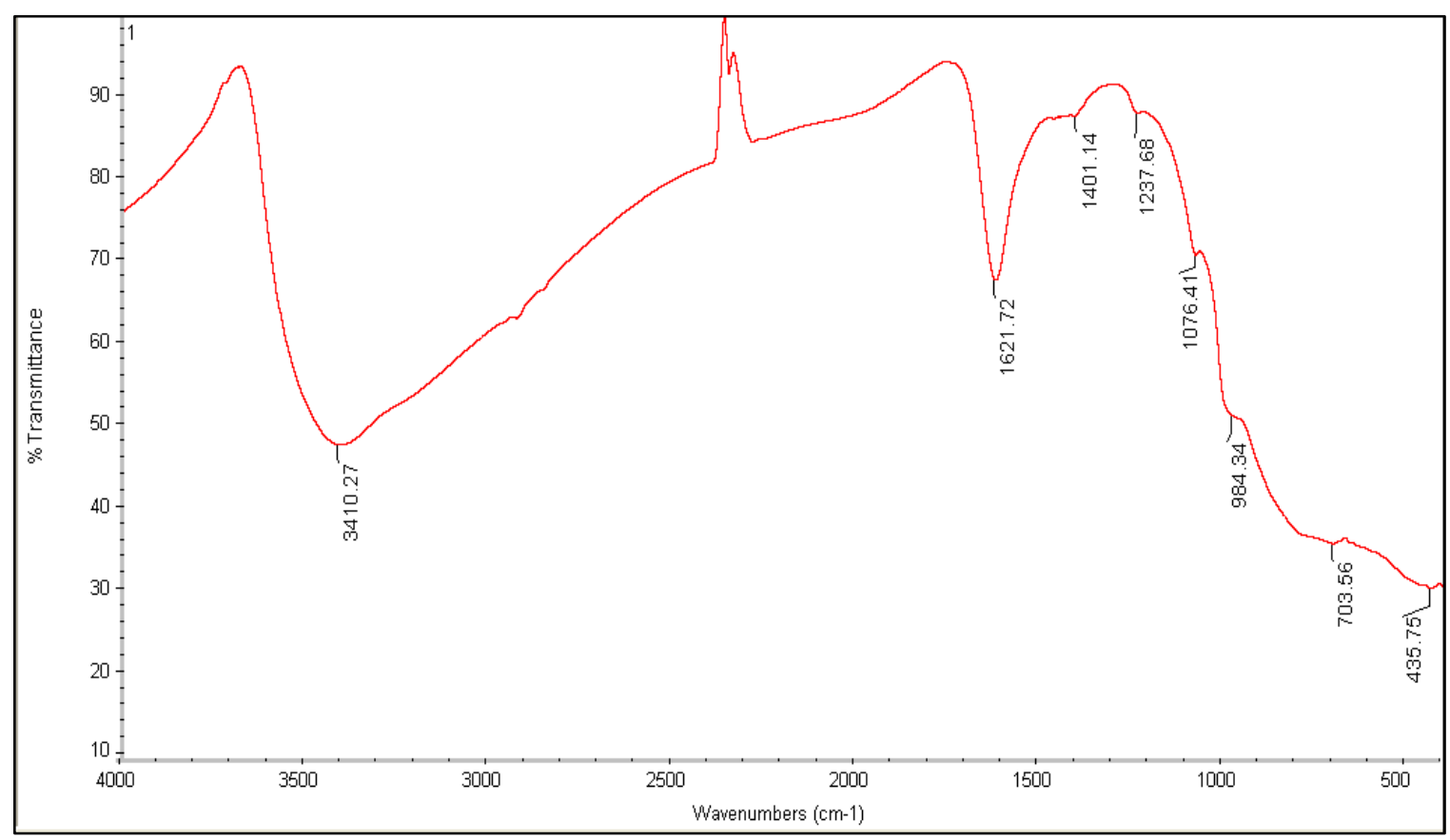

Fig. (1): FT-IR spectrum of zirconium vanadate $(\mathrm{ZrV})$.

Table. (1): FT-IR vibrations of prepared zirconium vanadate

\begin{tabular}{|c|c|}
\hline Peak assignment & Positions of the FT-IR band $\left(\mathrm{cm}^{-1}\right)$ \\
\hline$(\mathrm{H}-\mathrm{O}-\mathrm{H})$ streching/bending & 3410,1622 \\
$(\mathrm{~V}-\mathrm{OH}),(\mathrm{Zr}-\mathrm{OH})$ bending & 1401 \\
$(\mathrm{~V}-\mathrm{O})$ stretching/bending & 984,817 \\
$(\mathrm{~V}-\mathrm{O})$ stretching & 703 \\
$(\mathrm{Zr}-\mathrm{O})$ stretching & 436 \\
\hline
\end{tabular}




\section{$X$-ray diffraction $(X R D)$ analysis}

The amorphous structure (AS) of $\mathrm{ZrV}$ gel was confirmed by the XRD analysis as shown in Fig. 2. In some cases, AS is much better than the crystal structure (CS) in which the diffusion of eluent is more widespread in the amorphous material than in the crystalline material, resulting in an increase in the yield of elution [27]. From the other side, AS is more chemically stable, resulting in a high purity of ${ }^{47} \mathrm{Sc}$ eluate [34].

\section{Titration curve of $\mathrm{ZrV}$}

The $\mathrm{pH}$ plays an important role in the uptake and nature of the $\mathrm{ZrV}$ sorbent. Fig. 3. shows that $\mathrm{ZrV}$ has a point of zero charge (PZC) at $\mathrm{pH} 4.8$. PZC implies that the surface charge density (SCD) is equal to zero. The literature stated that $\mathrm{PZC}$ for $\mathrm{ZrO}_{2}$ was located in the range 4 to 8 , while vanadate was found at $\mathrm{pH} 4.2$ [34, 35]. The $\mathrm{ZrV}$ sorbent has a point of zero $\mathrm{pH}$ titration at $\mathrm{pH}$ 5.5. The amphoteric sorbent is known to have a positively charged surface at $\mathrm{pH}$ values lower than its PZC and to have a negatively charged surface at $\mathrm{pH}$ values greater than its PZC. ZrV behaviour in the acid medium was observed to act as an alkaline substance, so the $\mathrm{pH}$ increased higher than the blank curve as shown in Fig. 3 , may be due to the release of $\mathrm{OH}^{-}$ions in the solution from $\mathrm{ZrV}$ gel. While $\mathrm{ZrV}$ gel acts as an acidic substance in the alkaline medium due to a lower $\mathrm{pH}$ value than a blank curve due to the release of $\mathrm{H}^{+}$ions from the $\mathrm{ZrV}$ gel.

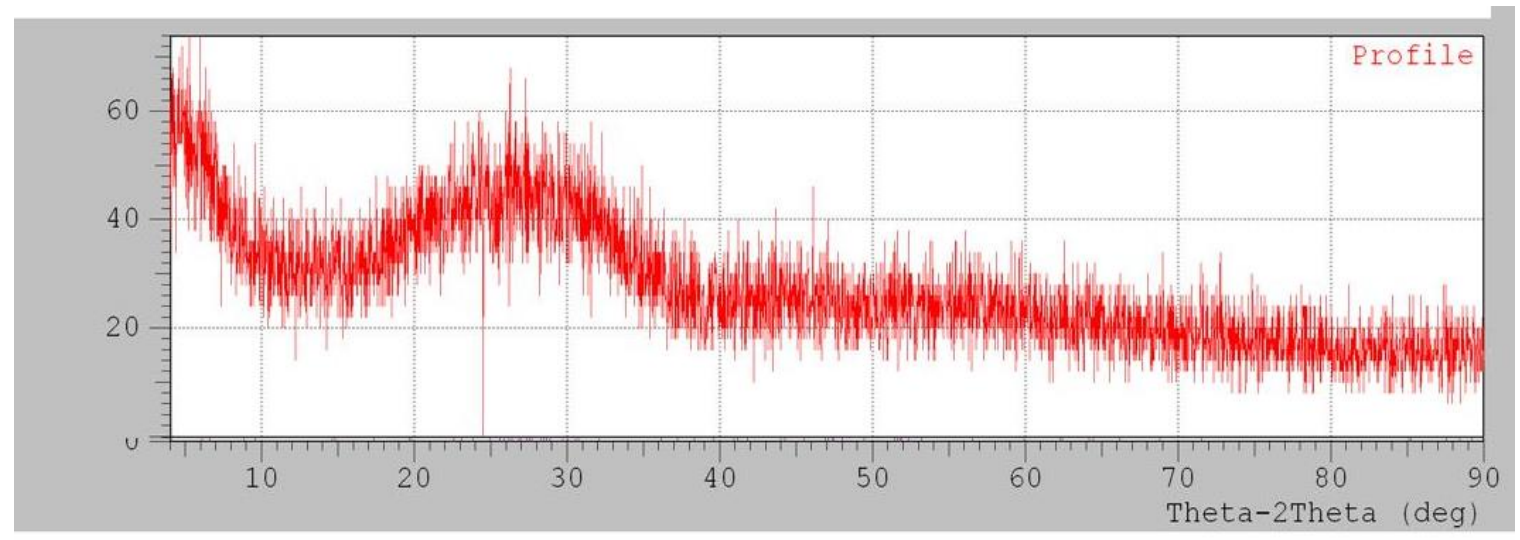

Fig. (2): XRD pattern of ZrV gel

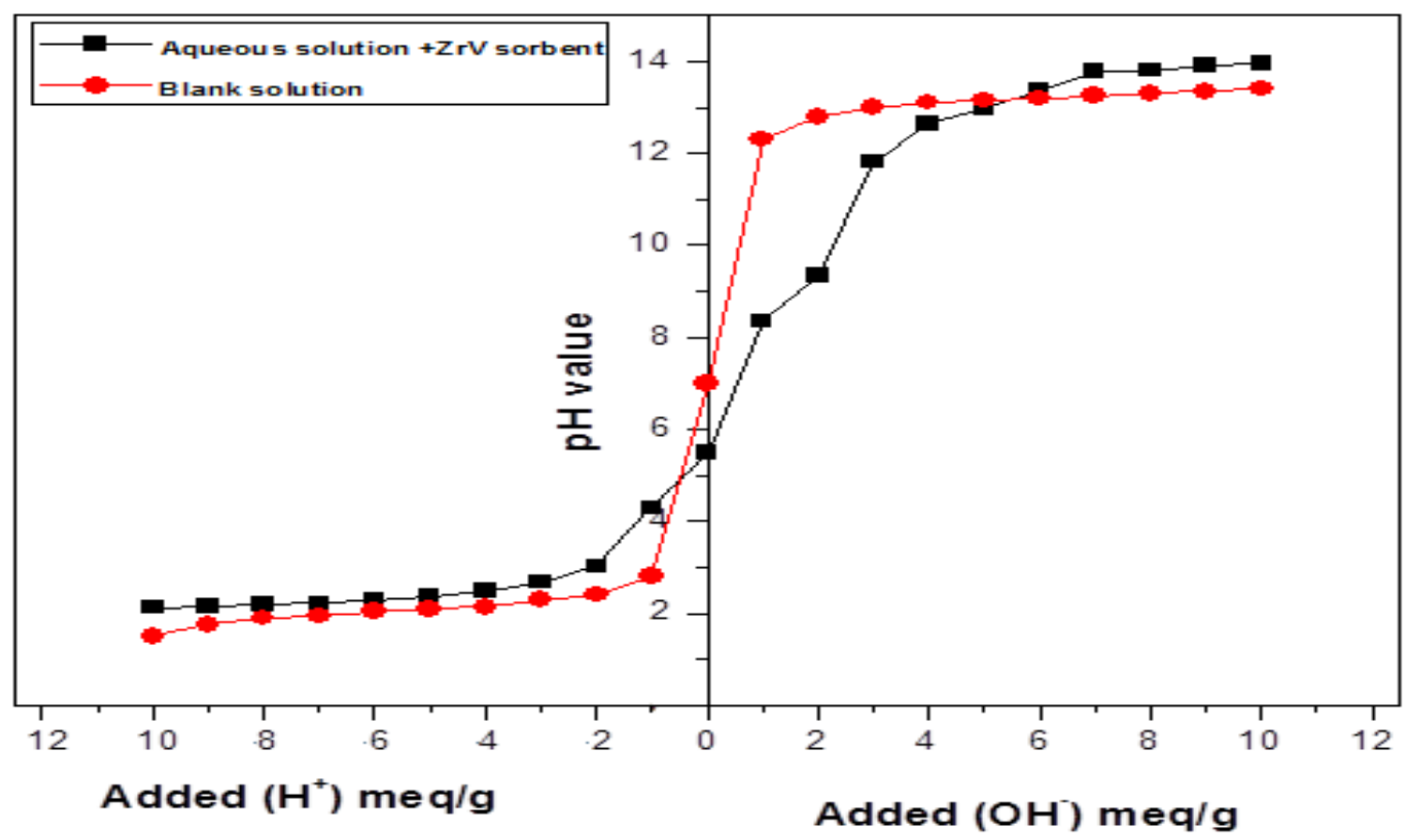

Fig. (3): Acid-base titration curve of $\mathrm{ZrV}$ 
Chemical species of $\mathrm{Ca}(\mathrm{II})$ and $\mathrm{Sc}(\mathrm{III})$ in aqueous solution using chemical equilibrium diagrams

Fig. 4 and 5., represent aqueous species of $\mathrm{Ca}(\mathrm{II})$ and $\mathrm{Sc}(\mathrm{III})$ at different $\mathrm{pHs}$, where $\mathrm{pH}$ ranges from 2 to 12 using chemical equilibrium diagrams [30]. $\mathrm{Ca}^{2+}$ is dominant with the presence of a further contribution of $\mathrm{H}^{+}$ions at $\mathrm{pH} 1$, which decreases by increasing $\mathrm{pH}$ to $\mathrm{pH} 5 . \mathrm{CaCl}(\mathrm{OH})_{2}$ starts to form at $\mathrm{pH} 2$ and increases by an increase in $\mathrm{pH}$ up to $\mathrm{pH} 9$ as shown in Fig. 5 . While $\mathrm{Sc}^{3+}$ is dominant with the existence of $\mathrm{Sc}(\mathrm{OH})^{2+}$ and $\mathrm{H}^{+}$species only at $\mathrm{pH}$ 1-2 range as shown in Fig. 5 ., where $\mathrm{H}^{+}$ions decreased with an increase in the other contributions of $\mathrm{Sc}(\mathrm{OH})_{2}{ }^{+}, \mathrm{Sc}_{2}(\mathrm{OH})_{2}{ }^{4+}$ and $\mathrm{Sc}_{3}(\mathrm{OH})_{5}{ }^{4+}$ ions by increasing the $\mathrm{pH}$ from 2 to $4.5, \mathrm{Sc}(\mathrm{OH})_{3}$ precipitate is formed higher than $\mathrm{pH} 4.5$.

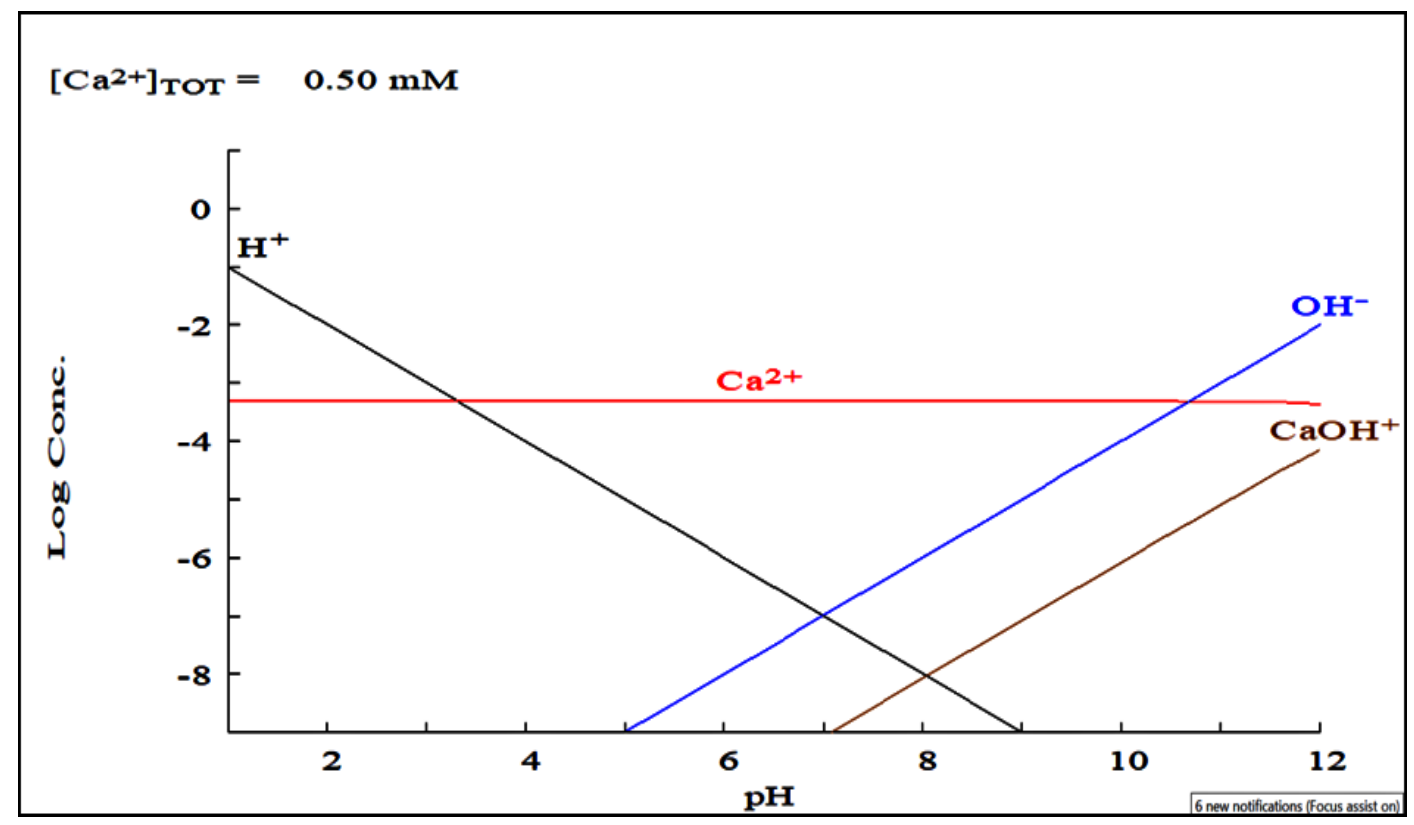

Fig. (4): Calcium species in $0.5 \mathrm{mM} \mathrm{Ca(II)} \mathrm{in} \mathrm{aqueous} \mathrm{solution} \mathrm{as} \mathrm{a} \mathrm{function} \mathrm{of} \mathrm{pH}$

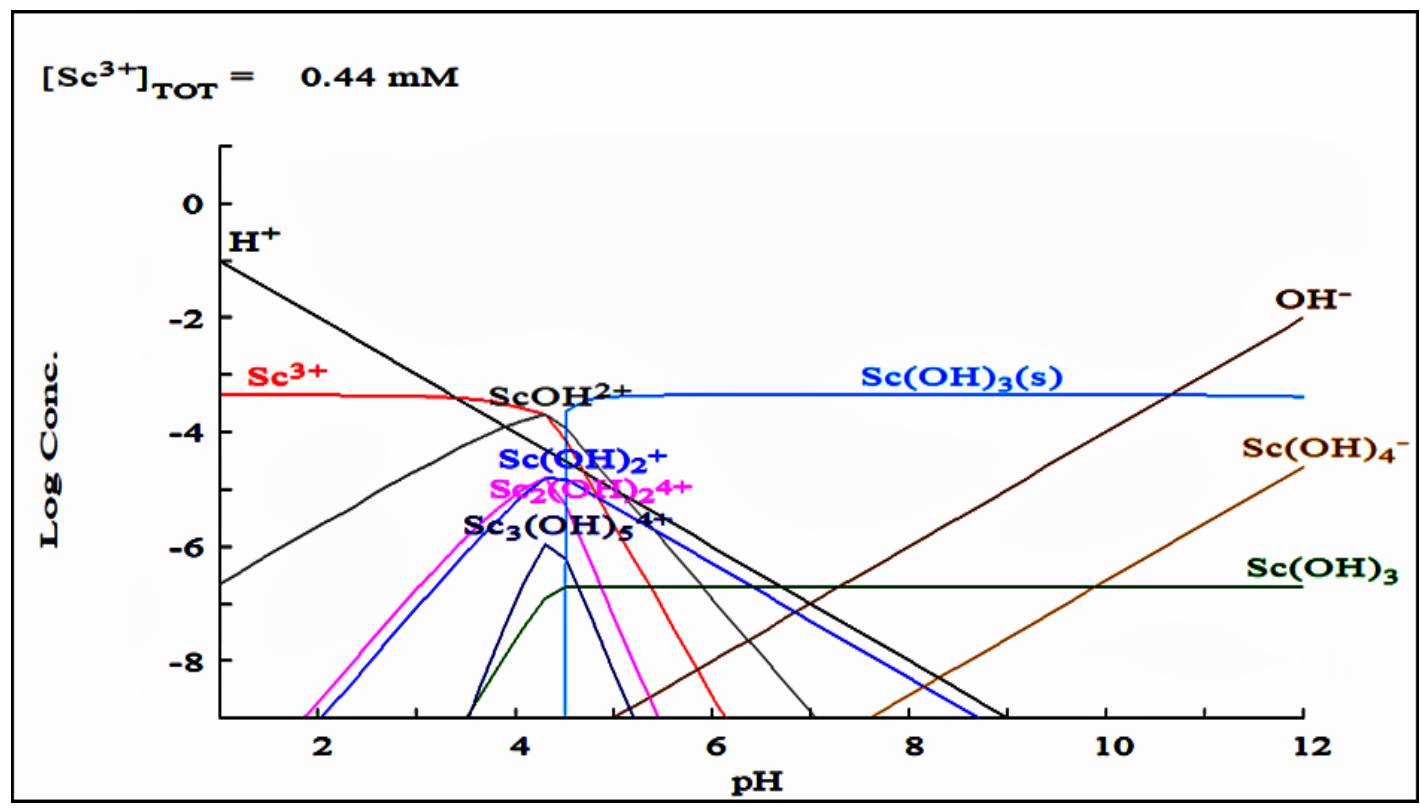

Fig. (5): Scandium species in $0.44 \mathrm{mM} \mathrm{Sc(III)}$ in aqueous solution as a function of $\mathrm{pH}$ 
Effect of $\mathrm{HNO}_{3}$ and $\mathrm{HCl}$ concentrations on $\mathrm{K}_{d}$ of $\mathrm{Sc}^{3+}$ and $\mathrm{Ca}^{2+}$ using $\mathrm{ZrV}$ matrix

The variation of $\mathrm{K}_{d}$ values of ${ }^{47} \mathrm{Sc}$ (III) and ${ }^{47} \mathrm{Ca}$ (II) ions as a function of $\mathrm{HNO}_{3}$ or $\mathrm{HCl}$ concentration using the $\mathrm{ZrV}$ matrix is demonstrated in Fig. 6. The results showed that ${ }^{47} \mathrm{Sc}$ (III) was strongly adsorbed from the range 0.001$0.01 \mathrm{M}$ of $\mathrm{HNO}_{3}$ or $\mathrm{HCl}$ to the $\mathrm{ZrV}$ matrix, higher and lower of these concentrations, the $\mathrm{K}_{\mathrm{d}}$ of ${ }^{47} \mathrm{Sc}$ (III) decreased, while ${ }^{47} \mathrm{Ca}$ (II) was weakly adsorbed to the full range of $\mathrm{HNO}_{3}$ or $\mathrm{HCl}$ concentrations and its $\mathrm{K}_{\mathrm{d}}$ values were relatively constant. $\mathrm{Sc}(\mathrm{III})$ may be formed as $\mathrm{ScCl}(\mathrm{OH})_{2}, \mathrm{Sc}(\mathrm{OH})_{3}$ and $\mathrm{Sc}(\mathrm{OH})_{4}$ species at $\mathrm{pH}>4$ as shown in Fig. 5 ., as a result of the presence of $\mathrm{Ca}^{2+}$ ions in the reaction mixture, the final solution $\mathrm{pH}$ increases to 8 in water, [36], but in the presence of low concentration of $\mathrm{HNO}_{3}$ or $\mathrm{HCl}(0.01-$ $0.001 \mathrm{M})$, the exist of $\mathrm{Ca}^{2+}$ ions shift solution $\mathrm{pH}$ to 3-5. These formed species have a high uptake towards the $\mathrm{ZrV}$ matrix, which acts as an anion exchanger based on its surface that carries positive charge in the acidic medium as seen in titration curve in Fig. 3., as well as the chemical reaction that could be achieved between $\mathrm{ZrV}$ matrix and $\mathrm{ScCl}(\mathrm{OH})_{2} . \quad \mathrm{K}_{\mathrm{d}}$ values, then decreased at a high concentration of $\mathrm{HNO}_{3}$ or $\mathrm{HCl}(>0.1 \mathrm{M})$ may be due to the $\mathrm{pH}$ of reaction mixture being shifted to a lower $\mathrm{pH}(\mathrm{pH}$ 1-2) at a high concentration of acids forming $\mathrm{H}^{+}$and $\mathrm{Sc}^{3+}$ ions, which are less reactive to the $\mathrm{ZrV}$ matrix acting as an anion exchanger in an acidic medium as seen in the titration curve Fig. 3. On the other hand, the $\mathrm{K}_{\mathrm{d}}$ values of $\mathrm{Sc}^{3+}$ decreased at low concentration of $\mathrm{HNO}_{3}$ or $\mathrm{HCl}(<0.001 \mathrm{M})$, which may be due to the hydrolysis and precipitation of $\mathrm{Sc}^{3+}$ that begins at $\mathrm{pH}>5[37,38]$. In addition to, $\mathrm{K}_{\mathrm{d}}$ values using nitric acid are higher than hydrochloric acid values, which may be attributed to lower nitrate anion hydration energy than the chloride anion hydration energy [39].

\section{Performance of ${ }^{47}$ Sc elution}

Fig. 7. displays the elution curve of ${ }^{47} \mathrm{Sc}(\mathrm{III})$ and ${ }^{47} \mathrm{Ca}$ (II) at $0.5 \mathrm{ml} / \mathrm{min}$ flow rate, from $600 \mathrm{mg} \mathrm{ZrV}$ matrix packed in a column of $5 \mathrm{~mm}$ inside diameter using $60 \%$ acetone- $0.2 \mathrm{M} \mathrm{HCl}$ as an eluent. It is clear that the concentration of acid has a high effect on the effectiveness of the $\mathrm{ZrV}$ matrix as a sorbent material. The most suitable concentration of $\mathrm{HCl}$ or $\mathrm{HNO}_{3}$ for ${ }^{47} \mathrm{Sc}$ (III) retention, which coincided with ${ }^{47} \mathrm{Ca}$ (III) elution, is $0.001 \mathrm{M}$. The acid concentration greater than $0.5 \mathrm{M}$ contributes to the partial dissolution of the $\mathrm{ZrV}$ matrix as seen in Table (2), which also indicates the elution yield of ${ }^{47} \mathrm{Sc}$ using various eluents. The elution yield of ${ }^{47} \mathrm{Sc}$ increased from 40 to $55 \%$ by increasing the $\mathrm{HNO}_{3}$ concentration from 0.1 to $0.5 \mathrm{M}$ and, in the case of $\mathrm{HCl}$, the elution yield of ${ }^{47} \mathrm{Sc}$ decreased from 64 to $59 \%$ by increasing its concentration from 0.2 to $0.5 \mathrm{M}$. The rise concentration of $\mathrm{HCl}$, or $\mathrm{HNO}_{3}$ above 0.5 $\mathrm{M}$ resulted in the partial dissolution of the $\mathrm{ZrV}$ matrix, giving a pale yellow color in the ${ }^{47} \mathrm{Sc}$ eluate. Also, the elution yield using $\mathrm{HCl}, \mathrm{HNO}_{3}$ or ammonium acetate does not provide the appropriate results. Elution yield increased to approximately $88 \pm 2.2 \%$ in about $5 \mathrm{ml}$ solution of $60 \%$ acetone- $0.2 \mathrm{M} \mathrm{HCl}$, due to acetone is quickly water miscible [40, 41]. The low concentration of $\mathrm{HCl}$ (relatively low concentration due to the high concentration having a deleterious effect on the $\mathrm{ZrV}$ matrix) with different ratios of the acetone concentration is studied to form the hydration field around the Sc cation that is sufficiently weakened to allow the chloride anions to replace the water in the coordinating shell, where the non-volatile organic matter metal chloride complex is formed [42], in order to elute ${ }^{47} \mathrm{Sc}$ from $\mathrm{ZrV}$ matrix.Therefore, scandium-chloride complex may be formed in anion form in acetone-HCl mixture solution and increased the stability of $\left[\mathrm{ScCl}_{4}\right]^{-}$in the presence of two acetone molecules as shown in the Fig.8.

Table (3), demonstrated the different ion exchangers used to separate ${ }^{47} \mathrm{Sc}^{3+}$ from ${ }^{47} \mathrm{Ca}^{2+}$ based on the elution yield and the purity of the eluted ${ }^{47} \mathrm{Sc}[2,42]$. It was observed that the separation process on the $\mathrm{ZrV}$ matrix also provides the highest yield and purity of ${ }^{47} \mathrm{Sc}$ elution by comparing it with other exchangers using different methods.

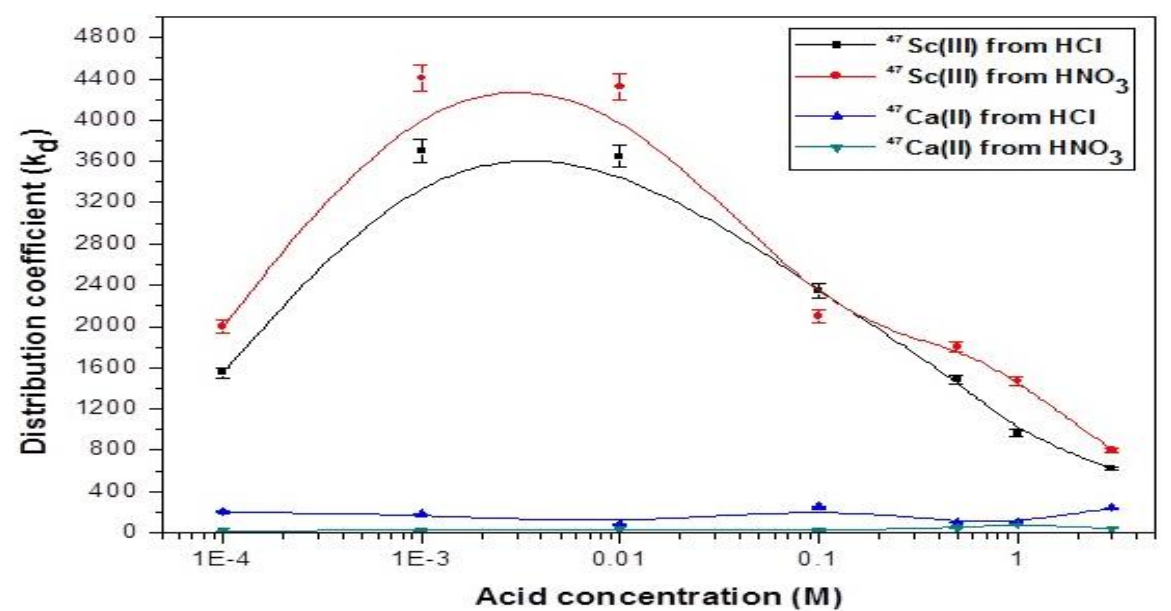

Fig. (6): Variation of the $\mathrm{K}_{\mathrm{d}}$ values of ${ }^{47} \mathrm{Sc}(\mathrm{IIII})$ and ${ }^{47} \mathrm{Ca}(\mathrm{II})$ ions from different concentrations of $\mathrm{HCl}$ and/or $\mathrm{HNO}$ to the ZrV matrix. 


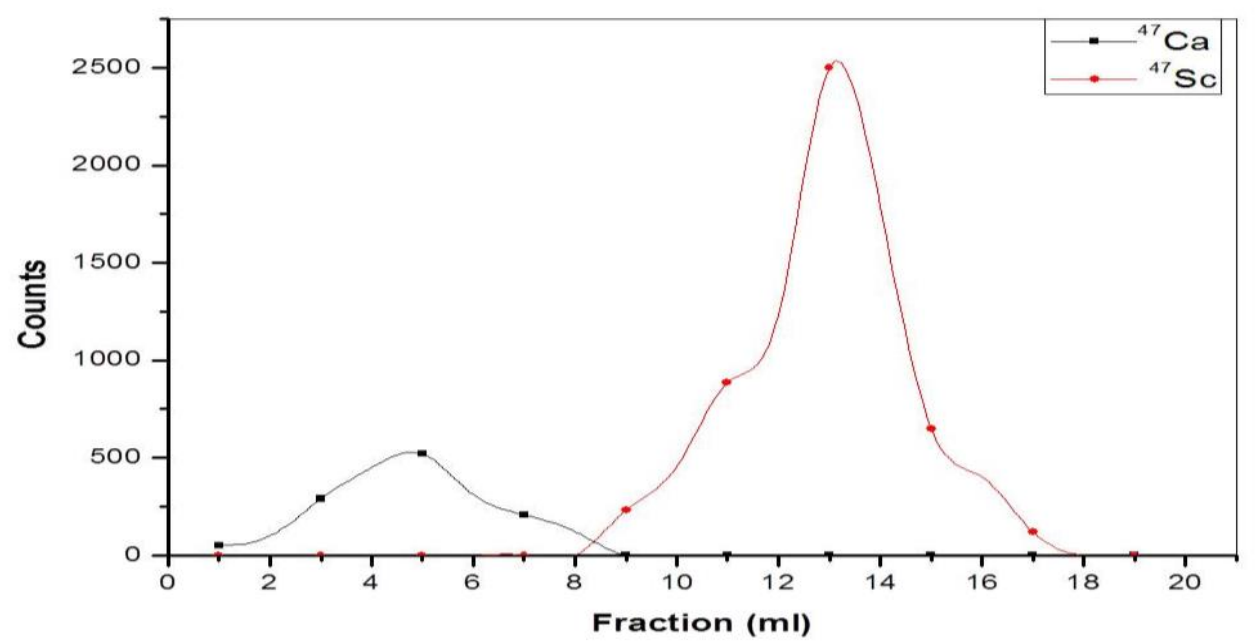

Fig. (7): Elution curve of ${ }^{47} \mathrm{Ca}(\mathrm{II})$ and ${ }^{47} \mathrm{Sc}(\mathrm{III})$ using $600 \mathrm{mg}(\mathrm{ZrV})$ column $(5 \mathrm{~mm}$ i.d) at flow rate $0.5 \mathrm{ml} / \mathrm{min}$.

Table (2): The elution yield of ${ }^{47} \mathrm{Sc}$ from the ${ }^{47} \mathrm{Sc}-\mathrm{ZrV}$ matrix using column dimensions $(10 \mathrm{~cm}$ length $0.5 \mathrm{~cm} \mathrm{ID),} 600 \mathrm{mg} \mathrm{ZrV}$, and different eluents at flow rate $0.5 \mathrm{ml} / \mathrm{min}$.

\begin{tabular}{cc}
\hline Eluents & ${ }^{47}$ Sc elution yield (\%) \\
\hline $0.1 \mathrm{M} \mathrm{HNO}_{3}$ & $40 \pm 2.0$ \\
$0.5 \mathrm{M} \mathrm{HNO}_{3}$ & $55 \pm 2.5$ \\
$1 \mathrm{M} \mathrm{HNO}_{3}$ & Partially dissolving ZrV matrix \\
$0.2 \mathrm{M} \mathrm{HCl}$ & $64 \pm 3.0$ \\
$0.5 \mathrm{M} \mathrm{HCl}$ & $59 \pm 2.8$ \\
$1 \mathrm{M} \mathrm{HCl}$ & $70 \pm 3.5$ \\
$40 \%$ acetone in $0.2 \mathrm{M} \mathrm{HCl}$ & $75 \pm 4.0$ \\
$50 \%$ acetone in $0.2 \mathrm{M} \mathrm{HCl}$ & $\mathbf{8 8} \pm \mathbf{2 . 2}$ \\
$\mathbf{6 0 \%}$ acetone in $\mathbf{0 . 2 M ~ H C l}$ & $75 \pm 4.5$ \\
$70 \%$ acetone in $0.2 \mathrm{M} \mathrm{HCl}$ & dissolving ZrV matrix \\
\hline
\end{tabular}

Table (3): Comparison of radioscandium separation methods from calcium targets

\begin{tabular}{|l|c|c|c|}
\hline \multicolumn{1}{|c|}{ Matrix } & Elution yield (\%) & Ca concentrations in the eluted ${ }^{47}$ Sc product (ppm) & References \\
\hline DOWEX 50 & 80.00 & $<1$ & {$[35]$} \\
Chelex 100 & 85.00 & $<1$ & {$[20,37]$} \\
UTEVA extraction resin & 79.00 & $<1$ & {$[20]$} \\
Filtration (0.2 $\mu$ ) & 96.00 & $<1$ & {$[20]$} \\
P (AA-AN)-NPs CuO composite & $78 \pm 1.2$ & 0.05 & {$[38]$} \\
ZrV (this work) & $88 \pm 2.2$ & 0.05 & \\
\hline
\end{tabular}




\section{Reaction mechanism}

Roy et al., 2002 [29] described $\mathrm{ZrV}$ as an inorganic ion exchanger and has a chemical formula, namely $\mathrm{ZrO}_{2} . \mathrm{V}_{2} \mathrm{O}_{5} .2 \mathrm{H}_{2} \mathrm{O}$. Fig. 8, reveals the proposed chemical reaction between the $\mathrm{ZrV}$ matrix and the proposed $\mathrm{ScCl}(\mathrm{OH})_{2}$ species for absorption of ${ }^{47} \mathrm{Sc}$ on $\mathrm{ZrV}$ matrix followed by an elution using $60 \%$ acetone- $0.2 \mathrm{M} \mathrm{HCl}$ with high elution yield.<smiles>O=[V]1([O-])O[Z10](O)(O)O[Te](=O)([O-])O1</smiles>

$\mathrm{ZrV}$ matrix (S)
ZrV matrix (S)<smiles>O=[Te]1([O-])O[V](O)([18OH])O[W](=O)([O-])O1</smiles>

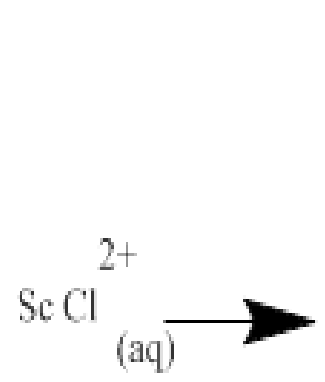

$60 \%$ acetone in $0.2 \mathrm{M}$ $\mathrm{HCl}$

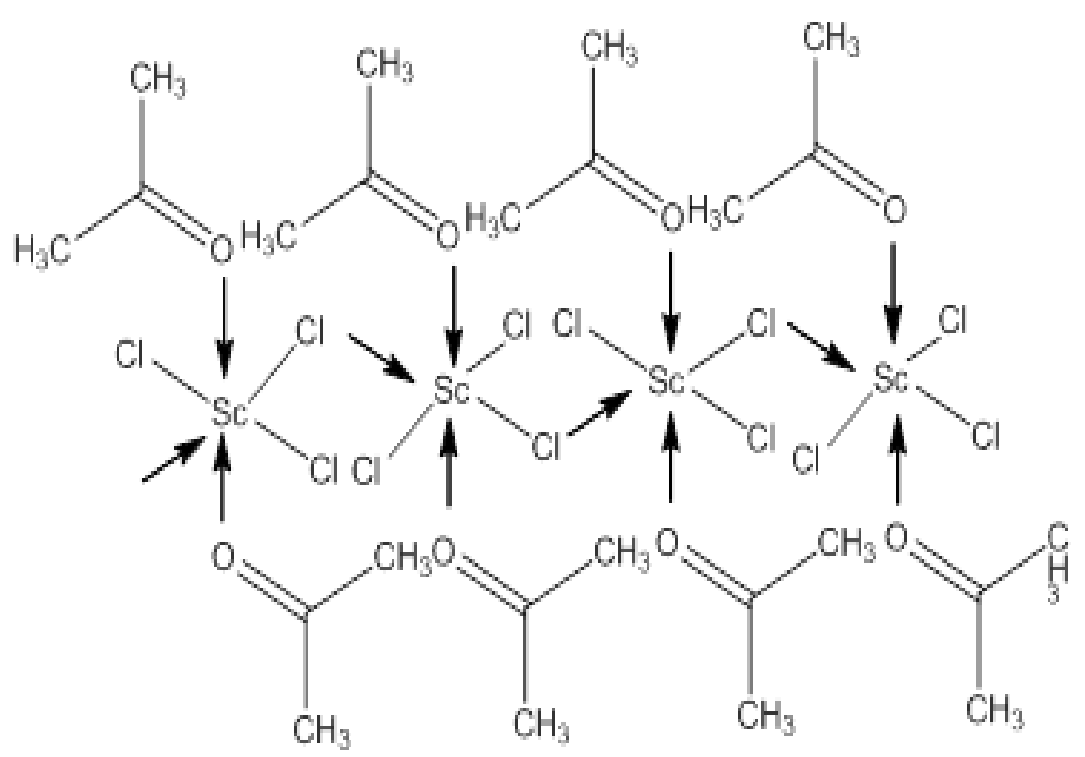

Fig. (8): Suggested mechanism for the separation of ${ }^{47} \mathrm{Sc}$ from $\mathrm{ZrV}$ matrix 


\section{Quality control performance on the eluted ${ }^{47} S c(I I I)$ Radiochemical purity}

In order to investigate the radiochemical purity of the eluted ${ }^{47} \mathrm{Sc}$, the development of the eluted ${ }^{47} \mathrm{Sc}$ solution on chromatogrphic paper was carried out in two different developing solvents. The radio-chromatogram in Fig. 9(a and b )., shows that one major peak was accomplished at $R_{f}=0.1$ using saline as a mobile phase, while in the other developing solvent (acetic acid: water, $1: 1 \mathrm{v} / \mathrm{v})$ the peak was moved to the higher $\mathrm{R}_{\mathrm{f}}$ value $\left(R_{\mathrm{f}} \sim 1\right)$ with the solvent front. The radiochemical purity of ${ }^{47} \mathrm{Sc}$ as $\mathrm{Sc}^{3+}$ ions could be evaluated to be $99.9 \pm 0.09 \%$.

\section{Chemical purity}

Despite $\mathrm{Ca}$ is non-toxic, an excess of ${ }^{47} \mathrm{Ca}^{2+}$ radioactivity may have a deleterious effect, due to an increase in the undesired radioactive dose during the labelling process of pharmaceutical compounds using ${ }^{47} \mathrm{Sc}$. Furthermore, the presence of $\mathrm{Ca}^{2+}$ in the eluted ${ }^{47} \mathrm{Sc}$ is more hazardous to the radiochemical yield of ${ }^{47} \mathrm{Sc}$ pharmaceutical compounds due to its competition with ${ }^{47} \mathrm{Sc}^{3+}[43,44]$. Table (2), shows that the concentration of $\mathrm{Ca}^{2+}$ in the decayed ${ }^{47} \mathrm{Sc}$ solution did not exceed 0.05 $\mathrm{ppm}$, therefore the eluted ${ }^{47} \mathrm{Sc}$ is suitable for medical applications, due to its value below the allowable level (10 ppm) [45]. On the other hand, for the purpose of extracting acetone from ${ }^{47} \mathrm{Sc}$ eluate, the literature data showed that dibasic potassium phosphate $\left(\mathrm{K}_{2} \mathrm{HPO}_{4}\right)$, was used to separate acetone by $100 \%$, which is also used safely as a buffering agent [46].

\section{Radionuclidic purity}

Fig. 10 (a)., showed the gamma-ray spectrum of the radioactive calcium target dissolved in $1 \mathrm{M} \mathrm{HCl}$ and measured using the HPGe detector connected to the multichannel analyzer to indicate the main gamma peaks associated with ${ }^{47} \mathrm{Sc}$ at $159.3 \mathrm{keV}$ and ${ }^{47} \mathrm{Ca}$ at 488.9 , 807.8 and $1296.8 \mathrm{keV}$. On the other hand, Fig.10 (b)., explained the ${ }^{47} \mathrm{Sc}$ gamma-peak, which was measured directly after the elution to determine the purity of ${ }^{47} \mathrm{Sc}$ radionuclide, that was found to be $>99.98 \pm 0.001 \%$. There are two main reasons for the inability to determine gamma energy lines of ${ }^{46} \mathrm{Sc}\left(\mathrm{t}_{1 / 2}=83 \mathrm{~d}\right)$, either in the irradiated calcium target or in the eluted ${ }^{47} \mathrm{Sc}$ solution: the small cross-section of ${ }^{44} \mathrm{Ca}(\mathrm{n}, \gamma){ }^{45} \mathrm{Ca}$ reaction $(0.8 \mathrm{~b})$ and the long half-life of ${ }^{45} \mathrm{Ca}\left(\mathrm{t}_{1 / 2}=163 \mathrm{~d}\right)$. The ${ }^{45} \mathrm{Ca}$ then decayed by beta to produce ${ }^{45} \mathrm{Sc}$ as a stable isotope with very small quantities, which will be activated again by thermal neutrons to produce ${ }^{46} \mathrm{Sc}$ that could not be determined by gamma analysis.
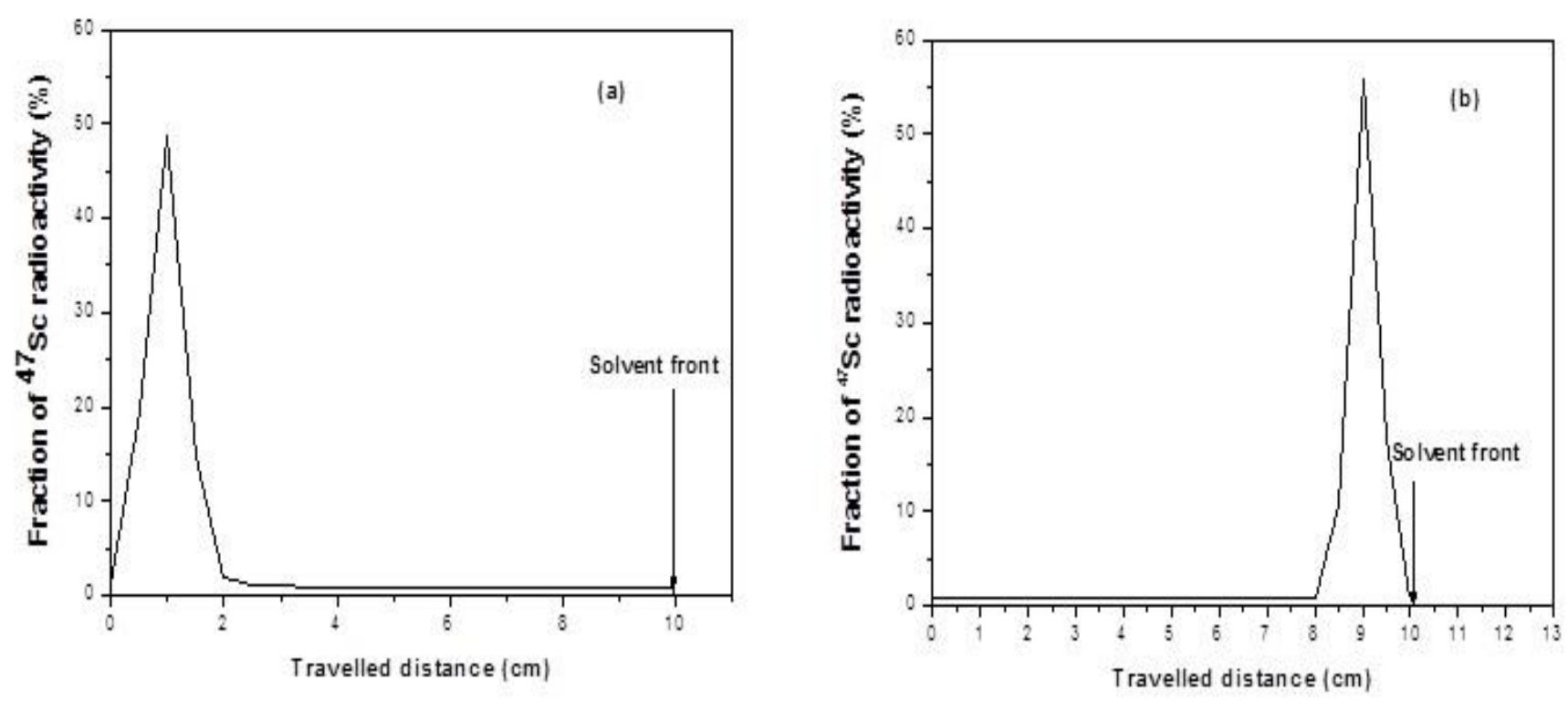

Fig. (9): The eluted ${ }^{47} \mathrm{Sc}$ radio-chromatogram using (a) saline solution (0.9\% $\mathrm{NaCl}$ solution) and (b) acetic acid : water (1:1 v/v) 


\section{CONCLUSION}

The distribution coefficients of ${ }^{47} \mathrm{Sc}$ and ${ }^{47} \mathrm{Ca}$ radionuclides between aqueous solutions $\left(\mathrm{HCl}\right.$ or $\mathrm{HNO}_{3}$ solution) and the $\mathrm{ZrV}$ gel were studied by batch technique and the results refer to loading of ${ }^{47} \mathrm{Sc}$ from $0.001 \mathrm{M} \mathrm{HNO}_{3}$ or $\mathrm{HCl}$. The sorption process of ${ }^{47} \mathrm{Sc}$ was interpreted by studying the chemical equilibrium diagram study, which revealed that the chemical species formed as a function of $\mathrm{pH}$, represented the chemical absorption. Where, the chemical reaction that could be done by two groups of hydroxides on the $\mathrm{ScCl}(\mathrm{OH})_{2}$ interacting with the two hydrogen ions $\left(\mathrm{H}^{+}\right)$on the $\mathrm{ZrV}$ gel. In addition, the physical adsorption was verified by the titration curve, which revealed the sorbent charge of $\mathrm{ZrV}$ (+ve charge $<\mathrm{pH} 4.8$ ) and the formed species of scandium $\left(\mathrm{ScCl}_{4}{ }^{-}\right)$as a function of $\mathrm{pH}$. The elution efficiency of about $88 \pm 2.2 \%$ was obtained for ${ }^{47} \mathrm{Sc}$ using $60 \%$ acetone in $0.2 \mathrm{M} \mathrm{HCl}$. The eluted ${ }^{47} \mathrm{Sc}$ has a radionuclidic purity of $>99.98 \pm 0.001 \%$ in an oxidation state (III).

The results refer to loading of ${ }^{47} \mathrm{Sc}$ from $0.001 \mathrm{M}$ $\mathrm{HNO}_{3}$. The elution efficiency of about $88 \pm 2.2 \%$ was obtained for ${ }^{47} \mathrm{Sc}$ using $60 \%$ acetone in $0.2 \mathrm{M} \mathrm{HCl}$, with a ${ }^{47} \mathrm{Sc}$ radionuclidic purity of $>99.98 \pm 0.001 \%$ in an oxidation state (III).
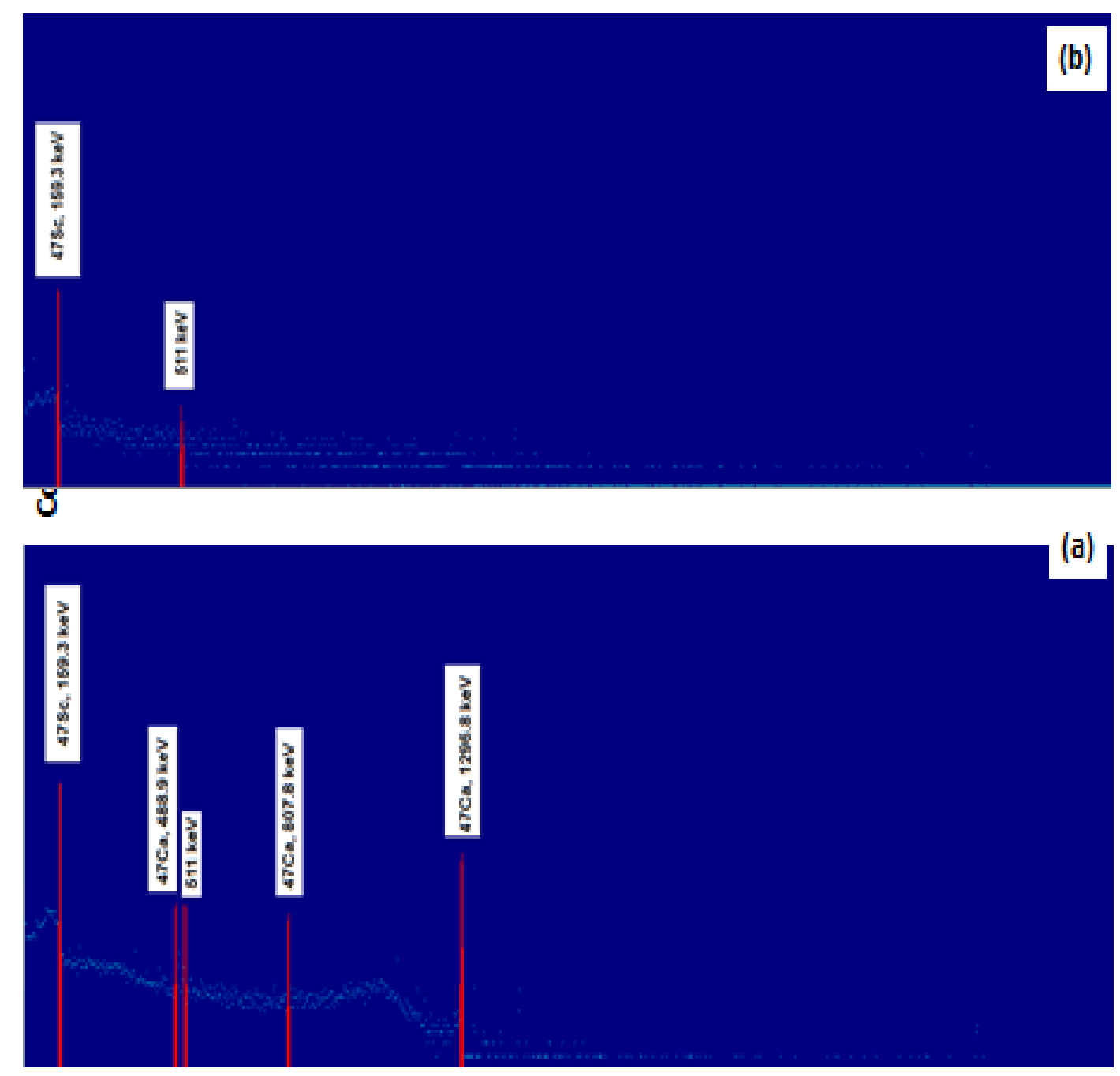

Fig. (10): Gamma-ray spectrum of (a) the dissolved irradiated natural calcium target (b) the eluted ${ }^{47} \mathrm{Sc}$ 


\section{ACKNOWLEDGMENTS}

The authors are grateful to the International Atomic Energy Agency for funding our work through the IAEA Coordinated Research Project No: 20566.

\section{REFERENCES}

[1] Domnanich, K.A., Müller, C., Bene š ová, M., Dressler, R., Haller, S., Köster, U., Ponsard, B., Schibli, R., Türler, A., van der Meulen, N.P.,( 2017). ${ }^{47} \mathrm{Sc}$ as useful $\beta$--emitter for the radiotheragnostic paradigm: a comparative study of feasible production routes. EJNMMI radiopharm. chem. 2 (1):5-14.

[2] Müller,C., Bunka, M., Haller, S., Köster, U., Groehn, V., Bernhardt, P., Van der Meulen, N., Türler, A., Schibli, R.,(2014). Promising prospects for ${ }^{44} \mathrm{Sc}-{ }^{47} \mathrm{Sc}$-based theragnostics: application of ${ }^{47} \mathrm{Sc}$ for radionuclide tumor therapy in mice. J Nucl Med., 55(10):1658 - 1664.

[3] Pietrelli, L., Mausner, L.F., Kolsky, K.L., (1992). Separation of carrier-free $47 \mathrm{Sc}$ from tita-nium targets. J. Radioanal. Nucl. Chem. 157 (2): 335 345 .

[4] Majkowska, A., Neves, M., Antunes, I., Bilewicz, A., (2009). Complexes of low energy beta emitters ${ }^{47} \mathrm{Sc}$ and ${ }^{177} \mathrm{Lu}$ with zoledronic acid for bone pain therapy. Appl. Radiat. Isot. 67 (1): 11 13.

[5] Mausner, L. F., Kolsky, K. L., Joshi, V., Srivastava, S.C., (1998). Radionuclide development at BNL for nuclear medicine therapy. Appl Radiat Isot 49:285-294.

[6] Srivastava, S. C., (2011). Paving the way to personalized medicine: production of some theragnostic radionuclides at Brookhaven National Laboratory. Radiochim Acta 99:635640.

[7] Kolsky, K. L., Joshi, V., Mausner, L. F., Srivastava, S. C.,(1998). Radiochemical purification of no-carrier-added scandium- 47 for radioimmunotherapy. Appl. Radiat. Isot. 49 (12): $1541-1549$.

[8] Gizawy, M. A., Mohamed, N. M. A., Aydia, M. I., Soliman, M. A., Shamsel-Din, H. A.,(2020). Feasibility study on production of Sc-47 from neutron irradiated $\mathrm{Ca}$ target for cancer theranostics applications. Radiochimica Acta, 108 (3): 207-215.
[9] Gladney, E. S., Goode, W. E., (1979). Preparation of carrier-free ${ }^{47} \mathrm{Sc}$ by the $47 \mathrm{Ti}(\mathrm{n}, \mathrm{p})$ reaction with epithermal neutrons. Int. J. Appl. Radia. and Isoto., 30 (1): 65 -73.

[10] Srivastava S. C.,(2012). Paving the way to personalized medicine: production of some promising theragnostic radionuclides at Brookhaven National Laboratory. Semin Nucl Med. 42(3):151- 63 .

[11] Radhakrishnan, K.P., Owens, T.C., (1972). Separation of scandium and calcium by liquidliquid extraction using tributyl phosphate as solvent. J. Chem. Eng. Data 17 (4): 478 -482.

[12] Vyas, C.K., Park, J.H., Yang, S.D.,(2016). Application of extraction chromatographic techniques for separation and puri fi cation of emerging radiometals ${ }^{44 / 47} \mathrm{Sc}$. JRM 2 (2) .

[13] Severin, G.W., Gagnon, K., Engle, J.W., Valdovinos, H.F., Barnhart, T.E., Nickles, R.J., $\left(2012 b^{)}{ }^{44 g}\right.$ Sc from metal calcium targets for PET. AIP Conf. Proc. 1509, 125 -128 .

[14] Müller, C., Bunka, M., Reber, J., Fischer, C., Zhernosekov, K., Türler, A., Schibli, R.,( 2013). Promises of cyclotron-produced $44 \mathrm{Sc}$ as a diagnostic match for trivalent $\beta$--emitters: in vitro and in vivo study of a 44 Sc-DOTA-folate conjugate. J. Nucl. Med. 54 (12):2168 -2174.

[15] Krajewski, S., Cydzik, I., Abbas, K., Bulgheroni, A.,Simonelli, F., Holzwarth, U., Bilewicz, A., (2013).Cyclotron production of ${ }^{44} \mathrm{Sc}$ for clinical application. Radiochim. Acta 101 (5): 333 -338.

[16] Van der Meulen, N.P., Bunka, M., Domnanich, K.A., Müller, C., Haller, S., Vermeulen, C., Türler, A., Schibli, R.,( 2015). Cyclotron production of 44Sc: from bench to bedside. Nucl. Med. Biol. 42 (9): 745 - 751.

[17] Valdovinos, H.F., Hernandez, R., Barnhart, T.E., Graves, S., Cai, W., Nickles, R.J., (2015). Separation of cyclotron-produced ${ }^{44} \mathrm{Sc}$ from a natural calcium target using a dipentyl pentylphosphonate functionalized extraction resin. Appl. Radiat. Isot. 95:23 -29.

[18] Alliot, C., Kerdjoudj, R., Michel, N., Haddad, F., Huclier-Markai, S., (2015). Cyclotron production of high purity $44 \mathrm{~m}, 44 \mathrm{Sc}$ with deuterons from ${ }^{44} \mathrm{CaCO} 3$ targets. Nucl. Med. Biol. 42 (6):, $524-$ 529. 
[19] Kilian, K., Cheda, Ł ., Sitarz, M., Szkliniarz, K., Choiń ski, J., Stolarz, A., (2018). Separation of 44 Sc from natural calcium carbonate targets for synthesis of 44 Sc-DOTATATE. Molecules 23 (7):1787-1795.

[20] Minegishi, K., Nagatsu, K., Fukada, M., Suzuki, H., Ohya, T., Zhang, M.R., (2016). Production of scandium-43 and-47 from a powdery calcium oxide target via the nat ${ }^{44} \mathrm{Ca}(\alpha, \mathrm{x})$-channel. Appl. Radiat. Isot. 116:8-12 .

[21] Misiak, R., Walczak, R., W ąs, B., Bartyzel, M., Mietelski, J.W., Bilewicz, A., (2017). ${ }^{47}$ Sc production development by cyclotron irradiation of 48 Ca. J. Radioanal. Nucl. Chem. 313 (2): 429 -434 .

[22] Walczak, R., Krajewski, S., Szkliniarz, K., Sitarz, M., Abbas, K., Choiń ski, J., Jakubowski, A., Jastrz ębski, J., Majkowska, A., Simonelli, F., Stolarz, A., (2015). Cyclotron production of ${ }^{43} \mathrm{Sc}$ for PET imaging. EJNMMI Phys. 2 (1):33-40

[23] Gizawy , M.A., Aydia M.I. Abdel Monem , Islam M., Shamsel-Din H.A., Siyam T., (2019). Radiochemical separation of reactor produced Sc47 from natural calcium target using Poly(acrylamide-acrylic acid)/multi-walled carbon nanotubes composite. Appl. Radiat. Isot. 150: 87-94.

[24] Jing, Z., Zhang, G., Sun, X.F., Shi, X., Sun, W.,( 2014). Preparation and adsorption proprties of a novel superabsorbent based on multiwalled carbon nanotubes -xylan composite and poly (methacrylic acid) for methylene blue from aqueous solution.

[25] Harjula, R. nd J. Lehto, (1987). Separation of cesium from nuclear waste solutions with hexa cyano ferrate (II) and ammonium phosphomolybdate. Solvent Extr.. Ion Exch., 5: 343-.351.

[26] Lehto, J., R. Harjula and J. W allace, (1987). Adsorption of cesium on potassium cobalt hexacyanoferrate (II). J. Radioannal. Nucl. Chem., (111): 297-304.

[27] Aydia, M.I., El-Said, H., El-Sadek, A.A., ElAzony, K.M. (2018). Preparation and characterization of zirconium silico W-tungstate as a base material for $188 \mathrm{~W} / 188 \mathrm{Re}$ generator. Appl. Radiat. Isot. 142: 203-210.

[28] El-Said, H., El-Sadek, A.A., Aydia, M.I., ElAzony, K.M. (2018). Zirconium silicotungstate matrix as a prospective sorbent material for the preparation of ${ }^{113} \mathrm{Sn} /{ }^{113 \mathrm{~m}} \mathrm{In}$ generator. J. Radioanal. Nucl. Chem., 317 (3): 1341-1347.

[29] Roy K, Pal DK, Basus S, Dalia N, Susanta L.,( 2002). Synthesis of a new ion exchanger, zirconium vanadate, and its application to the separation of barium and cesium radionuclides at tracer. Appl. Radiat. Isot.57: 471-474.

[30] Puigdomenech,(2013). Make equilibrium diagrams using sophisticated algorithms (MEDUSA). Inorganic chemistry, Royal Institute of Technology, Stockhol, Sweden. Http//www.kemi.kth.se/medusa .

[31] Chakravarty, R., Chakraborty, S., Ram, R., Dash, A.( 2017). An electroama-lgamation approach to separate ${ }^{47} \mathrm{Sc}$ from neutron-activated ${ }^{46} \mathrm{Ca}$ target for use in cancer theranostics. Sep. Sci. Technol. 52(14): 2363-2369.

[32] Sharma, H. K., Sharma, N.,(2013). Synthesis and structural characterization of tin(IV)molybdotungstate-A heteropolyacid salt. Der Chem. Sin. 4: 182-189.

[33] Geng, Y., Zhang, P., Kuang, S.,(2014). Fabrication and enhanced visible-light photocatalytic activities of $\mathrm{BiVO}_{4} / \mathrm{Bi}_{2} \mathrm{WO}_{6}$ composites. RSC Adv 4:4605446059.

[34] Kosmulski, M.,(2009). pH-dependent surface charging and points of zero charge. IV. Update and new approach. J. Colloid and interface Sci. 337 (2): 439-446.

[35] Muhammad, S., Hussain, S. T., Waseem, M., Naeem, A.,(2012). Surface charge properties of zirconium dioxide. Iranian J. Sci. Tech. A4: 481486.

[36] Hussain, J., Tariq Jan, M., Korchef, A., Touaibi, M.,(2020). Effect of $\mathrm{pH}$ and temperature on calcium carbonate precipitation by $\mathrm{CO}_{2}$ removal from iron-rich water, Water and Environment Journal, 34: 331-341.

[37] Baes, C. F., Mesmer R. E. (1976). The Hydrolysis of Cations, Wiley Interscience, New York, NY, USA.

[38] Das, S, Behera, S.S., Murmu, B.M., Mohapatra, R.K., Mandal, D., Samantray, R., Parhi, P.K., Senanayake, G., (2018). Extraction of scandium(III) from acidic solutions using organo- 
phosphoric acid reagents: A comparative study Sep. Pur. Tech., 202: 248-258.

[39] Vyas, C. K., Joshirao, P. M., Manchanda, V. K. (2014). Perchloric acid a promising medium for the chromatographic separation of ${ }^{90} \mathrm{Y}$ from ${ }^{90} \mathrm{Sr}$. Sep. Purif. Technol. 124: 179-188.

[40] Robinson, J.W.,( 1960). Effect of organic and aqueous solvents on flame photometric emission and atomic absorption spectroscopy. Anal. Chim. Acta 23: 479-478.

[41] El-Azony, K. M.( 2011). Improving the separation of $\mathrm{Cu}(\mathrm{II})$ from $\mathrm{Zn}(\mathrm{II})$ based on an anion exchanger for the preparation a ${ }^{62} \mathrm{Zn} /{ }^{62} \mathrm{Cu}$ generator. Appl. Radia. and Isoto., 69 (9):11761180.

[42] El-Azony, K.M., I. smail Aydia M., El-Mohty, A.A.,(2011). Separation of $\mathrm{Cr}(\mathrm{III})$ from $\mathrm{Cr}(\mathrm{VI})$ by Triton X-100 cerium(IV) phosphate as a surface active ion exchange J .Radioanal. Nucl. Chem., 289 (2): 381-388.

[43] Mousa, A. M., Abdel Aziz, O. A., Al-Hagar, O. E. A., Gizawy, M. A., Allan, K. F., Attallah, M. F.,(2020). Biosynthetic new composite material containing $\mathrm{CuO}$ nanoparticles produced by Aspergillus terreus for ${ }^{47} \mathrm{Sc}$ separation of cancer theranostics application from irradiated $\mathrm{Ca}$ target. Appl. Radia. and Isoto., 166: 109389-109396.

[44] Martell A, Smith,R, Motekaitis,R. NIST Critically Selected Stability const-ants of Metal Complexes Database,(2004)

http://www.nist.gov/srd/nist46.cfm

[45] Galle, P., Masse, R. (Eds.),(1982). Radionuclides Metabolism and Toxicity. Masson, Paris.

[46] Xie, S., Song, W., Fu, C., Yi, C., Qiu, X.,(2018). Separation of acetone: from a water miscible system to an efficient aqueous two-phase system. Separ. Purif. Technol. 192: 55-61. 